\title{
La "Plaza de la Dignidad" como escenario de protesta. La dimensión cultural en la comprensión del acontecimiento de Octubre chileno
}

\author{
The "Plaza de la Dignidad" as a Scene of Protest. \\ The Cultural Dimension in understanding the Chilean October Event
}

\author{
Juan Pablo Paredes P. \\ Departamento de Ciencias Sociales, Universidad Católica del Maule \\ jparedes@ucm.cl
}

\begin{abstract}
Resumen
¿Cómo participaron los factores culturales del acontecimiento de Octubre en Chile? ¿Cómo se relacionaron entre sí tales factores? ¿Qué alcances tuvieron para la acción colectiva y la vida social? El artículo tiene como propósito realizar una lectura cultural del acontecimiento de Octubre. Para hacerlo, se propone un dialogo entre la sociología cultural y los estudios culturales, aplicados al movimiento de protesta de Octubre, recurriendo a herramientas de la investigación interpretativa. Se utiliza de manera ilustrativa la apropiación de Plaza Italia, en Santiago, por los manifestantes, para resaltar los elementos culturales y sus interacciones. Dentro de los hallazgos destaca la producción de encuadres para la movilización, la producción de una simbología e iconografía propia y el despliegue de performances que permiten definir a la Plaza misma como un artefacto de protesta. Posteriormente se discuten ciertos alcances de lo anterior para la sociedad civil. Se concluye con una proyección del trabajo y una breve reflexión sobre la relación ciencias sociales y humanidades para desplegar una estrategia interpretativa de investigación empírica.
\end{abstract}

Palabras clave: manifestación pública, sociedad civil, estudios culturales, sociología cultural, significados sociales.

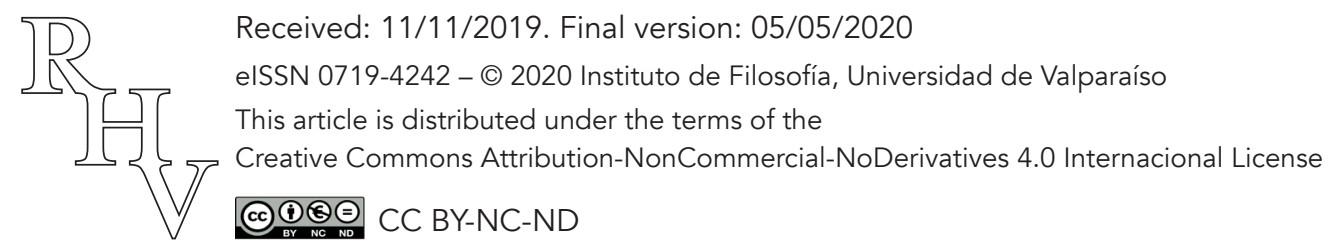


La "Plaza de la Dignidad" como escenario de protesta...

Juan Pablo Paredes P.

\begin{abstract}
How did cultural factors participate in the event of October in Chile? How were these factors related to each other? What implications did they have for collective action and social life? The purpose of the article is to carry out a cultural reading of the October event. To do this, a dialogue is proposed between cultural sociology and cultural studies, applied to the October protest movement, resorting to interpretive research tools. The appropriation of Plaza Italia, in Santiago, by the protesters, is used in an illustrative way to highlight the cultural elements and their interactions. Among the findings, the production of meaning based on motifs and frames stands out, the production of its own symbolism and iconography and the deployment of performances that allow defining the Plaza itself as an artifact of protest. Then certain scopes of the above for civil society are discussed. It concludes with a projection of the work and a brief reflection on the relationship between social sciences and humanities to deploy an interpretive strategy of empirical research.
\end{abstract}

Keywords: public demonstration, civil society, cultural studies, cultural sociology, social meanings.

\title{
1. Introducción
}

Lo acontecido a partir del 18 de Octubre del año 2019 en Chile, fue sin duda excepcional. El "no lo vimos venir" se utilizó como un recurso retórico frecuente en las esferas política, mediática y académica, para dar cuenta de su inesperada irrupción. Transcurrido un tiempo, las reflexiones han sido realizadas, los análisis propuestos y las explicaciones planteadas (Morales 2020; Peña 2020; Waissbluth 2020). En una de las formulaciones más serias en términos empíricos, Morales (2020) identifica cuatro crisis político-institucionales a la base de lo ocurrido: a) de participación; b) de representación; c) de confianza; d) de probidad pública y privada. En su explicación, Morales (2020) reduce los factores culturales a las dinámicas político-institucionales, restándole cualquier relevancia en lo ocurrido. Por su parte, desde la filosofía social, Peña (2020), introduce la dimensión cultural reduciéndola a los aspectos normativos y estructurales asociados al proceso de modernización del Chile y sus efectos, lejanos de las prácticas y significados de los propios actores movilizados, lo que nuevamente ubica lo cultural en un lugar subordinado. Desde el comentario político, Waissbluth (2020) relaciona la cultura con lo generacional, el cambio tecnológico y el individualismo, siendo parte de los factores secundarios que explican lo sucedido, junto a la economía política, el marco internacional, la institucionalidad política cerrada, la crisis de representación y confianza, o la criminalidad estructural, que tienen la prioridad. Por ende, no sorprende que tanto Peña como Waissbluth, utilicen el concepto de anomia para explicar el déficit normativo que le atribuyen a los manifestantes y a las protestas.

Revista de Humanidades de Valparaíso, 2021, No 17, 27-52

(c) $(1)(9)$ CC BY-NC-ND 
La "Plaza de la Dignidad" como escenario de protesta...

Juan Pablo Paredes P.

Las posiciones anteriores comparten una orientación explicativa de las causas que provocaron la ola de protestas, lo que les lleva a excluir lo cultural, en el caso de Morales (2020), o bien, en Peña (2020) y Waissbluth (2020), a reducir y limitar los alcances culturales en sus explicaciones. El gesto anterior es un rasgo común en los análisis de la acción colectiva, los movimientos sociales y las protestas en Chile. Pocos son los trabajos que dotan de centralidad a la dimensión cultural en el estudio de las protestas, lo que implica privilegiar no tanto las causas de las protestas y las movilizaciones, sino el cómo de su acontecer junto con captar algunas de sus consecuencias en los sentidos subjetivos, colectivos y públicos (Paredes 2013).

¿Cómo participaron los factores culturales del acontecimiento del 18 de Octubre en Chile? ¿Cómo se relacionaron con la acción social y colectiva? ¿Cómo se relacionaron entre sí tales factores? ¿Qué alcances tuvieron para la acción colectiva y la vida social? ¿Qué hipótesis interpretativas se pueden proyectar a partir de estos elementos? El trabajo intenta responder de manera oblicua estas interrogantes, a partir del supuesto que la dimensión cultural es muy relevante para la conformación del movimiento de protesta. Los elementos culturales presentes en el movimiento permiten comprender su emergencia, su permanencia y alcances para la vida social y la acción colectiva.

El escrito tiene como orientación tomar ciertas situaciones ejemplares acontecidas durante el primer mes de protestas en Santiago, al que llamaré el acontecimiento de Octubre (Araujo 2019), para ilustrar las formas en que lo cultural participó en ellos, junto con proponer algunas reflexiones teórico-metodológicas para el estudio de los movimientos de protestas (Jasper 2016). Por ende, el trabajo se propone con una finalidad exploratoria aplicada a una pretensión empírico-comprensiva y una más epistémica. La primera, apunta a destacar y analizar la presencia de elementos culturales en el acontecimiento de Octubre, utilizando las herramientas de la investigación interpretativa, a partir de la apropiación de la Plaza Italia por los manifestantes y el posterior cambio de su nombre. El segundo foco, presentado de manera tentativa e iniciática, apunta a dar pasos en la dirección de reimpulsar en las ciencias sociales el análisis cultural para el estudio del conflicto y las protestas sociales, argumentando a favor del vínculo entre ciencias sociales empíricas y herramientas interpretativas provenientes de las humanidades.

Para cumplir tales metas, el escrito continúa de la siguiente manera. El siguiente apartado, segundo, discute la relación entre protestas sociales y la dimensión cultural, para elaborar la categoría movimiento de protesta. El tercero, plantea la postura epistémico metodológica de la investigación interpretativa a partir del dialogo entre sociología cultural y estudios culturales. El cuarto expone el análisis cultural aplicado a la Plaza de la Dignidad como artefacto de protesta, sus performances y frames. El quinto propone una discusión sobre los efectos culturales del movimiento de protesta para la sociedad civil, a partir de un análisis del paisaje de sentido reconstruido. El texto cierra con una conclusión proyectiva y una reflexión sobre la utilidad de la vinculación entre ciencias sociales y humanidades para desarrollar el análisis cultural interpretativo.

Revista de Humanidades de Valparaíso, 2021, No 17, 27-52 
La "Plaza de la Dignidad" como escenario de protesta...

Juan Pablo Paredes P.

\section{Protestas sociales desde la dimensión cultural}

Una manifestación pública, siguiendo a Fillieule y Tartakowsky refiere a la ocupación colectiva y temporal, "de un lugar abierto, público o privado, y que directa o indirectamente conlleva la expresión de opiniones políticas" $(2015,24)$. A partir de tal definición, proponen estudiar la manifestación pública de acuerdo a cuatro propiedades: a) la ocupación momentánea de lugares físicos abiertos, de preferencia públicos, b) la expresividad de la acción, tanto para los propios participes como para los oponentes y los públicos, lo que da cierta idea de unidad simbólica, más no necesariamente una identidad; c) requiere de un número considerable de participantes que den la sensación de masividad y colectividad, y; d) el alcance político de la demostración pública, que puede ser intencional o un producto derivado de ella (Fillieule y Tartakowsky 2015).

La manifestación es una forma de protesta que implica la interacción concreta y simbólica entre diversos tipos de actores, en un espacio físico compartido y por un tiempo delimitado, que permite desplegar formas contenciosas de demandas sociopolíticas (Schuster 2005). Para fines del texto, la protesta social se expresa como una manifestación pública de carácter conflictivo y con alcance político, ya sea episodio o situación disruptiva, que incluye la interacción entre diferentes actores. Su relevancia radica en "la creación de una novedad y un quiebre con la serie de interacciones sociales que teníamos antes de ella" (Schuster 2005, 51). A partir de su continuidad temporal, las diversas acciones adquieren un carácter de unidad en virtud del sentido social que producen. Es decir, las protestas son puestas en escena que constituyen un registro público de los actos y actividades contenciosas que, en su unidad, constituyen una situación de conflicto (Cefaï 2011; Jasper 2016).

Utilizo el concepto de movimiento de protestas (Jasper 2016), para dar cuenta de la continuidad de manifestaciones públicas de índole político, ya sea de denuncia, reclamo o demanda, que introducen por ello alguna novedad en el contexto social en que ocurren. Sugiero que lo acontecido en Chile entre octubre y diciembre 2019, fue un movimiento de protesta que denunció un contexto de injusticia y formuló demandas políticas, pero también generó alcances culturales que deben atenderse. Prefiero el concepto movimiento de protesta por ser más descriptivo y sin la historia analítica ni la carga normativa de conceptos como movimientos sociales o revueltas populares, los que podrían ser etiquetas más justas para lo acontecido en Chile, pero que sobrepasan las pretensiones exploratorias del escrito.

Un punto relevante de los movimientos de protesta es que más allá de sus resultados políticos, produce alcances culturales dados por su emergencia, estabilización y rutinización (Jasper 2016). La dimensión cultural de la protesta es un área de indagación relativamente reciente en las ciencias sociales, en comparación a los estudios estructurales y racionales, aunque ha adquirido relevancia en su producción (Polleta 2004; Jasper 2010; Johnston 2016). Si bien sus antecedentes pueden encontrarse en análisis historiográficos

Revista de Humanidades de Valparaíso, 2021, No 17, 27-52

(c) $(1)(9)$ CC BY-NC-ND 
La "Plaza de la Dignidad" como escenario de protesta...

Juan Pablo Paredes P.

y humanísticos hace varias décadas, la producción y debate sobre la dimensión cultural en las protestas y los movimientos sociales sigue muy abierto (Ulrich, Daphi y Baumgarten 2014)

En el marco anterior, Rhys Williams (2004) señala que los estudios de la dimensión cultural en las protestas se concentraron, hasta inicios del 2000, en la dinámica interna de la movilización, prestando poca atención al entorno cultural de despliegue de sus prácticas, interacciones y relaciones. Las movilizaciones sociales y los movimientos de protestas ocurren en entornos culturales específicos y contextos delimitados, que deben ser considerados pues entregan claves de entendimiento del proceso, tanto como en sus consecuencias (Williams 2004; Ulrich, Daphi y Baumgarten 2014).

Para efectos del trabajo, entiendo lo cultural como una dimensión constitutiva de lo social, con una serie de alcances. Primero, lo cultural es un proceso de producción, creación y usos de significados, a través de acciones, interacciones, relaciones e instituciones, siendo una dimensión constitutiva de la vida social (Alexander 2003; Hall 2016; Williams 2003). Segundo, tal dimensión remite a expresiones compartidas por individuos, grupos y colectivos, encarnada en valores, normas, creencias, lenguaje, rituales, símbolos, íconos e identificaciones colectivas (Alexander 2003; Hall 2016; Swidler 1986; 1995), es decir, presenta una doble cara, simbólica y material. Tercero, tiene centralidad en la conformación, permanencia y éxito de los movimientos de protestas (Jasper 1997; 2016), tanto en su dimensión externa, ya sea en la creación de significados con resonancia social, su importancia en la forma de definir problemas públicos y abogar por formas de resolverlos influyendo en la política pública (Cefaï 2011; Paredes y Araya 2020). Como en su dimensión interna, para la creación de un sentido compartido de identidad en los participantes del movimiento (Polleta y Jasper 2001), lo cual es importante para crear un sentido de solidaridad, reclutar miembros y consolidar el compromiso (Polletta y Jasper 2001; Paredes y Otárola 2019). Entonces, el foco en lo cultural permite captar alcances internos a la movilización como a los planos externos de afectación en lo público.

En términos operativos, la dimensión cultural de la protesta puede diferenciarse en tres componentes (Jasper 2016; 2010). Primero, en formas cognitivas relativas a las creencias, las representaciones, el uso del leguajes y la creación de narrativas. Un segundo elemento remite a los aspectos morales, ya sea como principios explícitos o como intuiciones y sensibilidades. El último aspecto refiere a las emociones, sentimientos y afectos presentes en las acciones colectivas y las relaciones sociales. Creencias, valores, sentimientos, están presentes en las acciones colectivas, en los discursos y narrativas de la movilización, en las demandas políticas de las protestas, moldeando los significados que van perfilando el conflicto (Jasper 2016; 1997).

Recientemente, la investigación cultural de las protestas ha concitado más debates y se han realizado nuevas propuestas (Ulrich, Daphi y Baumgarten 2014; Johnston 2016; Jaspers 2016). Por ejemplo, Tavera y Johnston (2017), proponen captar la dimensión cul-

Revista de Humanidades de Valparaíso, 2021, No 17, 27-52

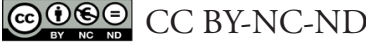


La "Plaza de la Dignidad" como escenario de protesta...

Juan Pablo Paredes P.

tural en las protestas en base a tres entradas empírico-analíticas: performance; encuadre (frame) y artefactos. Las performances remiten al despliegue dinámico de las actuaciones colectivas de los actores sociales, siendo las formas en que se les da cuerpo y presencia simbólico-material a los elementos ideacionales (Tavera y Johnston 2017), siempre en consideración de los contextos. Los marcos de sentido o encuadres, se corresponden con tales elementos ideacionales presentes en las performances, las creencias, los valores y las representaciones sociales que soportan la protesta. En relación con los artefactos culturales, estos son formas de materialización de performances y frames, en tanto objetos culturales concretos, no limitados a la puesta en escena corporal, cuya relevancia para la protesta es que "siempre son interpretados socialmente por sus públicos y forman parte de la continua creación de la cultura a través de una interpretación posterior" (Tavera y Johnston 2017, 16). Los artefactos de protesta operan como modos de concreción de las expresiones y sentidos, sin tener la temporalidad efímera del acto mismo (performance) ni de la enunciación pública (frame).

\section{A propósito del método: análisis cultural e interpretación}

El debate sobre los usos y sentidos de la cultura al interior de la sociología del norte global son relativamente recientes, en comparación con otros temas de mayor propiedad en las ciencias sociales. Una perspectiva de tal debate en Estados Unidos, ha sido la sociología cultural cuya finalidad es posicionar el análisis cultural en un lugar central al interior de las ciencias sociales. La Sociología Cultural (SC), al menos en la definición de J. Alexander (2003), entiende, analíticamente, la cultura como una variable independiente y autónoma de las variables estructurales y racionales. Tal autonomía analítica, le permite a Alexander hablar del programa sociológico fuerte para el análisis cultural. Anteriormente, otro programa de investigación proponía focalizar el análisis en la dimensión cultural de lo social en la producción de significados, pero a partir de entender lo cultural con una autonomía relativa de la estructura social. El programa de los Estudios Culturales (EECC), puso énfasis en los aspectos relativos al significado, las prácticas y los discursos en clave cultural, pero siempre vinculando con el poder (Williams 2003; Hall 2016), por lo mismo sus análisis se confundían en varios pasajes con los análisis de la ideología o la hegemonía. Por el contrario, la SC entiende lo cultural con completa autonomía analítica, aunque no empírica, lo que implica observar las formas en que el estudio de la significación social permite entretejer las realidades accionales e institucionales.

Sin embargo, a pesar de la diferencia epistémica, es posible encontrar ciertos paralelismos entre ambos programas de investigación que dotan a lo cultural de centralidad analítica. En primer lugar, ambos se alejan de la sociología de la cultura que la entendía como determinada y subordinada a la estructura, económica, política o social, es decir, intentan explicar lo social desde lo cultural mismo (Alexander 2003; Hall 2016), o por lo menos a contribuir a su explicación tomando en serio el elemento cultural (Lima Neto 2014). En

Revista de Humanidades de Valparaíso, 2021, No 17, 27-52

(c) $(1)(9)$ CC BY-NC-ND 
La "Plaza de la Dignidad" como escenario de protesta...

Juan Pablo Paredes P.

segundo lugar, ambos programas entienden lo cultural como un proceso social en el que se producen, reproducen, circulan y disputan significados. Tercero, el significado social se materializa en objetos, artefactos y prácticas culturales- aunque difieren en la forma en qué ocurre tal materialización (Lima Neto 2014). Por último, ambos programas trabajan en base a estrategias interpretativas de las ciencias sociales y de los estudios humanísticos (Reed 2011).

El punto anterior es el que resaltaré a continuación. Estudiar la dimensión cultural de la protesta requiere desplegar un tipo de investigación interpretativa capaz de presentar una modalidad de indagación que articule, de manera convincente, herramientas teórico-conceptuales con elementos empíricos. Isaac Reed (2011) expone que en las ciencias sociales existen modalidades habituales de dar cuenta de la relación entre teoría y datos empíricos, con sus propios criterios de validación, a los que llama modos epistémicos, e identifica el modo realista, el normativo y el interpretativo, con un alcance causal. En este último, el trabajo interpretativo hace afirmaciones fuertes sobre el orden simbólico a partir de las actuaciones observadas (Reed 2011). Tal trabajo interpretativo exige un compromiso ontológico con la eficacia del significado social y epistémicamente sugiere la idea de las consecuencias sociales de la significación, donde las redes de significado permiten o restringen la acción social, aportando en su formación. Esto lleva al reconocimiento de que construcciones conceptuales abstractas, como agencia, estructura, o solidaridad, requieren reinscribirse en procesos sociales, pues están incorporadas en intersecciones específicas de tiempo y espacio, en tanto formas de acción en un contexto cultural e histórico (como un movimiento de protesta), lo que da cierta capacidad explicativa a la interpretación (Reed 2011). Analíticamente, lo anterior remite a que los significados sociales intersectan tanto a estructuras como actores, siendo constitutiva de ellos, mediando la relación entre "evidencias" y "teorizaciones" en las explicaciones sociales.

Por lo tanto, el modo epistémico interpretativo busca reconstruir los significados de los actores como de sus contextos, para resignificar la evidencia empírica disponible en relación con ellos, tratando de elaborar una suerte de explicación interpretativa (Reed 2008). Para realizarla, Reed (2011), utiliza la metáfora "paisajes de sentido" (landscapes of meaning), que consiste en la capacidad de actores sociales de configurar un escenario de significados diverso y heterogéneo, que implica procesos de interpretación diferenciada, opuesta e incluso antagónica, en cada paisaje, poniendo énfasis en las diferentes texturas sociales y subjetivas que lo configuran, definiendo de paso su complejidad. Por ende, los paisajes de sentido no pueden reducirse a espacios isomórficos ni homogéneos, lo que los distingue de los campos de Bourdieu o los sistemas de Luhmann.

De acuerdo al sociólogo cultural, los paisajes de sentido están culturalmente definidos e históricamente situados, y permiten reconocer a los actores del paisaje, entender sus motivaciones, conocer sus competencias prácticas, especificar las interacciones y relaciones sociales, como dar cuenta de algunos mecanismos culturales, como los rituales, los estilos, las performances o los encuadres (Reed 2011). El modo epistémico interpretativo 
La "Plaza de la Dignidad" como escenario de protesta...

Juan Pablo Paredes P.

exige reposicionar a los actores sociales en el paisaje dentro del cual sus acciones se desenvuelven, y por el cual pueden interpretarse, para entender el sentido de la acción social, las formas de representación colectiva y de la experiencia de los actores, vinculadas a ciertas herramientas de la basta caja hermenéutica y comprensiva. Reed $(2008 ; 2011)$, para dar alcance explicativo al modo interpretativo, propone invertir la relación habitual entre explicación causal e interpretación mediante un gesto pragmático, es decir, buscar las consecuencias y los efectos causales de la acción social y colectiva.

Lo que propongo es aplicar el modo epistémico interpretativo para el análisis cultural, con el fin de reconstruir el paisaje de sentido relativo al movimiento de protesta en Plaza Italia, Santiago de Chile, desde el 18 de octubre al 14 de noviembre del 2019. Para hacerlo sigo la propuesta de Tavera y Johnston (2017), considerando los tres alcances de la cultura reconocido por Jasper $(2016 ; 1997)$. Aunque, privilegio el trabajo sobre artefactos culturales de la protesta de Octubre, se utilizan también los elementos ideacionales y discursivos, como los performáticos (Alexander y Mast 2011; Taylor 2012). Este paisaje se conforma a partir de escenas culturales en las que se desarrollan las performances, se materializan los encuadres y se dejan ver los artefactos. Las escenas son una conjunción de interacciones, relaciones y actuaciones colectivas que funciona tanto como espacio de experiencia y condensación situacional (Fischer-Litche 2011), que permite enlazar performances, frames y artefactos en la producción de significados compartidos, y a través de ellas reconstruir el paisaje de sentido de ese mes de movilización en Plaza Italia.

Las siguientes interpretaciones se realizaron a partir de un conjunto de materiales, basados en la observación participante de algunas jornadas de protesta, como en el uso de fuentes secundarias y de bibliografía especializada.

\section{Escenas de la revuelta primaveral chilena}

\subsection{El marco cultural y contextual}

A continuación presento de manera ilustrativa, las protestas desde el 18 de Octubre al 14 de Noviembre en Plaza Italia, a modo de ejemplificar el análisis cultural para reconstruir su paisaje de sentido. Pero antes, es necesario realizar una contextualización de lo ocurrido en la primavera chilena del 2019, resaltando ciertos elementos del trasfondo cultural previo a su ocurrencia.

El 4 de Octubre 2019, el gobierno de S. Piñera promulgó un alza en los pasajes del metro de Santiago, de 30 pesos nacionales. Frente a esto, un grupo de estudiantes secundarios realizó un llamado a evadir el pasaje sin pagar, que tuvo mucho eco en el mundo estudiantil. Desde el 14 de octubre de 2019, el mundo estudiantil mediante el eslogan "evadir/no pagar, otra forma de luchar", hizo público el descontento social con la medida de subir el coste del transporte público, poniendo en escena la denuncia, junto a la capacidad de la ciudadanía de oponerse a las decisiones de la institucionalidad política,

Revista de Humanidades de Valparaíso, 2021, No 17, 27-52

(c) $(1)(9)$ CC BY-NC-ND 
La "Plaza de la Dignidad" como escenario de protesta...

Juan Pablo Paredes P.

mediante el recurso a la desobediencia civil (Celikates 2016). El acto de los estudiantes es reprimido por las fuerzas policiales, bajo la solicitud de la gerencia del metro y con la venia del Gobierno, lo que significó que la desobediencia pasara del metro a las calles de Santiago. Los enfrentamientos entre estudiantes y carabineros, con el apoyo de los guardias privados del metro, desencadenaron un conjunto de nuevos eventos de tensión y protestas en escala ascendente, no solo en el centro de Santiago, sino en gran parte de la red de metro (Palacios 2020). Días después, el 18 de Octubre, se produjo un estallido social sin precedente en la historia reciente del país (Márquez 2020), que derivó en un movimiento de protestas que duró más de cuatro meses, sorteando incluso parte de las vacaciones estivales, y solo puesto en pausa por la pandemia COVID-19, a mediados de marzo 2020.

La respuesta del gobierno de S. Piñera al estallido del viernes 18 de Octubre, fue declarar Estado de Excepción Constitucional, primero en Santiago, luego a todo el país (Palacios 2020). Posteriormente pronunció un discurso belicista contra las protestas, al señalar que Chile libraba una guerra contra un enemigo poderoso, reprimiendo fuertemente las manifestaciones sociales (Somma et al. 2020; Navarro y Tromben 2019). Por casi una semana, Chile recordó los tiempos de la dictadura con los militares en la calle y la vida civil subordinada al poder militar. La literatura destaca lo violento del escenario sociopolítico tanto por la dinámica represiva como por actos vandálicos derivados de la manifestación (Somma et al. 2020; Palacios 2020; Márquez 2020). Violencia que se mantuvo hasta diciembre, aunque con variaciones en su intensidad.

En particular, la represión policial fue excesiva en cuanto al uso de fuerza y dirigida a todo tipo de manifestante, violento o pacífico, tanto que provocó resultados de muertes o heridos de gravedad (ACNUDH 2019). También se constataron hechos de torturas y abusos sexuales a manifestantes (Palacios 2020; Somma et al. 2020). Destaca del umbral de brutalidad policial, la cantidad de personas que sufrieron daño ocular en alguno de sus ojos, ya sea una ceguera parcial en uno de sus ojos, o por haber sufrido ceguera total (HRW 2019). El gobierno los calificó como incidentes aislados, sin embargo los informes de las comisiones internacionales que estuvieron en Chile, condenaron la represión policial debido a su recurrencia o sistematicidad, indicando la necesidad de prácticas de reparación (HRW 2019; ACNUDH 2019). Tal soporte internacional, avaló políticamente una acusación constitucional al Ministro del Interior, Andrés Chadwick, que fue aprobada por el congreso durante el mes de diciembre.

Después de un mes de manifestaciones, desde el llamado a evadir el pasaje por los estudiantes, el 15 de noviembre, se firmó el acuerdo por la paz y una nueva constitución, pacto político suscrito por la mayoría de las fuerzas políticas para dar una salida institucional al conflicto que amenazaba no solo al Gobierno sino a la política en general, remarcando las distancias entre la clase política y el mundo social movilizado (Somma et al. 2020; Palacios 2020). El acuerdo constitucional, se acompañó por un llamado a la paz entendido como el cese de las manifestaciones sociales y protestas populares pues eran

Revista de Humanidades de Valparaíso, 2021, No 17, 27-52

(c) $(1)(9)$ CC BY-NC-ND 
La "Plaza de la Dignidad" como escenario de protesta...

Juan Pablo Paredes P.

un foco de violencia, mientras la represión continuó sin disminuir el uso de la fuerza. Si bien el acuerdo del 15 de noviembre redujo la masividad de las manifestaciones públicas (Somma et al. 2020), siguieron ocurriendo tanto en forma pacífica como confrontacional, y con bastante presencia hasta fines de diciembre, manteniendo su desarrollo ajeno a la presencia de fuerzas políticas. Junto a su recurrencia, el repertorio de manifestaciones fue amplio y diverso, no solo limitado a la ocupación pública, también se dieron banderazos, cacerolazos, cicletadas, expresiones artísticas, entre otras.

Más allá de la gestión del gobierno que incidió en la fuerza del movimiento de protesta (Morales 2020), cuatro factores culturales del contexto (Jasper 2016; Reed 2011; Williams 2004), permiten situar el análisis posterior. Primero, se da una continuidad en la protesta social desde 2011, como recurso de la ciudadanía y del mundo popular para expresar sus malestares y demandas (COES 2020). Segundo, la respuesta gubernamental e institucional es principalmente condenatoria y represiva frente a las manifestaciones sociales y ciudadanas (COES 2020). La represión como respuesta se acompaña, en particular en el ciclo post2006, de la responsabilización de la violencia a los actores sociales y su criminalización por parte de la clase política y los medios (Centro Derechos Humanos UDP 2012). Tercero, el modo de resolución del conflicto es entre actores políticos, en espacios institucionales y sin la participación de los actores sociales, siguiendo una lógica elitista implementada desde el retorno a la democracia (PNUD 2015). Por último, la existencia de un clima favorable a la crítica, ya sea mediante la denuncia de alguna forma de injusticia o desigualdad social, o la demanda y reclamos de actores colectivos, que dota de cierta legitimidad las causas ciudadanas y colectivas de los últimos lustros (PNUD 2019). Estos elementos se sostienen en lógicas culturales más asentadas en los últimos 30 años, como son la naturalización de las jerarquías y de los privilegios, del autoritarismo sobre la autoridad, y de la confrontación entre fuerzas o poderes (Araujo 2019)

\subsection{Plaza de la Dignidad como escenario: performances y sentimientos morales}

El movimiento de protesta de octubre desplegó una apropiación del espacio en torno a plazas y calles, como el recurso más fuerte de su repertorio. Bajo la consigna "la marcha más grande"- complementada por alguna característica del lugar en que se realizó- se convocaron un conjunto de manifestaciones públicas masivas por todo Chile, en un formato híbrido entre marchas y ocupaciones del espacio público, dependiendo del número de participantes en las convocatorias. En Santiago, el principal foco fue la ocupación de la Plaza Italia, centro de reunión permanente para las actividades colectivas y masivas (Márquez 2020; Lin 2019), en las que se realizan diversos rituales, desde celebrar un triunfo deportivo hasta presentar a la sociedad reclamos y demandas sociales- no tanto al poder político porque para aquello el destino es el Palacio de la Moneda (Lin 2019)-. Republicanamente hablando, es un foco de congregación popular con valor simbólico.

Revista de Humanidades de Valparaíso, 2021, No 17, 27-52

(c) $(1)(9)$ CC BY-NC-ND 
La "Plaza de la Dignidad" como escenario de protesta...

Juan Pablo Paredes P.

Desde que estalló la movilización, la Plaza Italia se transformó en el lugar de congregación de las manifestaciones para denunciar el abuso del modelo social y económico. Foco inicial de las demandas contra los militares en las calles y la represión de los primeros días, el motivo fue recuperar su uso público. Al mismo tiempo, fue uno de los espacios que permitió entretejer relaciones de reconocimiento entre causas diversas o de apoyo mutuo y autodefensa entre los actores sociales que se congregaban en ella. La Plaza Italia y sus alrededores, sufrieron cambios en su uso y fisonomía (Márquez 2020), pero junto con ello, también en sus significados y sentires, siendo uno de los focos culturalmente más productivos del proceso, aunque no el único. Muchas de las plazas importantes de las ciudades chilenas tuvieron un destino similar, aunque con variaciones en su masividad, persistencia e intensidad. Aunque una de las características particulares del acontecimiento de Octubre en Santiago fue la apropiación del espacio público, por lo anterior, lo sucedido con la Plaza Italia es un caso ejemplar para ilustrar un paisaje rico en contenido cultural y con alcances políticos.

Desde el día siguiente, la Plaza Italia fue foco del conflicto, siendo la zona cero del mismo. Mientras la plaza y los alrededores fue copada por militares y carabineros, manifestantes- entre ellos algunas autoridades políticas- llegaron a reclamar su liberación como el regreso de los militares a sus cuarteles. Los manifestantes armados con sus voces, cacerolas, celulares, bicicletas, o piedras, se oponían sin miedo (Lin 2019) a la militarización de la plaza. La respuesta fue con balines, bombas lacrimógenas, fusiles y vehículos bélicos. Tal fue la escena durante todo ese fin de semana.

La plaza se transformó en un artefacto espacial, como punto de reunión para la resistencia y la creación colectiva. Fue un lugar que posibilitó una serie de escenas durante su ocupación, debido a que no es solo una plaza en un sentido tradicional, sino una red de espacios públicos e infraestructuras con profundas significaciones sociales y ciudadanas (Lin 2019), actuando ella como escenario para un conjunto de performances y encuadres asociados al movimiento de protesta.

El lunes 21 de Octubre, la plaza recibió manifestantes de manera masiva, quienes definieron las prácticas que poco a poco se harían habituales, como las de autodefensa, autocuidado y autosustentación. También establecieron interacciones y relaciones sociales, desplegaron actuaciones político-culturales diversas. Pintaron las paredes aledañas con grafitis, murales y rayados alusivos al movimiento de protesta sus causas y demandas (Márquez 2020), definiendo el conjunto de motivos que sostuvo las protestas. Lienzos y pancartas florecieron en torno a la plaza, apropiándose del lugar, dejando en evidencia la forma en que se produce y redefine socialmente el espacio por las manifestaciones (Fernández 2013; Berroeta y Sandoval 2014; Cuevas y Paredes 2018). Las consignas que marcaron las protestas fueron, "no son treinta pesos, son treinta años", que dio cuenta de la herencia neoliberal que produjo serias injusticias sociales; "Chile despertó", refirió a la capacidad de actuación y respuesta de la ciudadanía. Ambas fueron los motivos que definieron el encuadre de la movilización y parte de su narrativa.

Revista de Humanidades de Valparaíso, 2021, No 17, 27-52

(c) $(1)(9)$ CC BY-NC-ND 
La "Plaza de la Dignidad" como escenario de protesta...

Juan Pablo Paredes P.

La televisión y otros medios comunicacionales cubrieron las protestas. Con ello, comenzó a dibujarse la escena cotidiana en la plaza durante ese mes. A los días hacían su presencia algunos connotados personajes asociados a la cultura popular, como el "estúpido y sensual Spiderman", la tía "Pikachú", o la figura del "Negro Matapacos", aquel perro que acompañó las protestas estudiantiles del 2011, junto a grupos pertenecientes a las barras bravas del fútbol nacional, estudiantes y otros colectivos, que en sus interacciones realizaban cánticos, hicieron música y bailaron, entretejiendo y reforzando el vínculo común como el reconocimiento recíproco entre los manifestantes, cristalizando una fuerte identificación colectiva (Flesher Fominaya 2010; Polleta y Jasper 2001). Tal identificación colectiva, se reforzó en la exclusión de las fuerzas policiales y militares, de las autoridades de gobierno, como del mundo político en general, estableciendo una frontera antagónica (Laclau 2005) con ellos.

La frontera entre fuerzas policiales y manifestantes, acrecentaron la lucha por el espacio (Márquez 2020; Lin 2019). Se consolidó la definición de las primeras líneas, como formas de división del trabajo durante la ocupación de la plaza. La primera línea manifestante se especializó en la autodefensa y protección de los activistas en los enfrentamientos con la policía o en los momentos de represión (Lin 2019). La primera línea de cuidados, llamadas brigadas de salud, cumplieron las tareas de atención a manifestantes heridos, golpeados o afectados por la represión policial, fomentando el autocuidado. Ambas primeras líneas definieron sus funciones y estaban equipadas adecuadamente para ellas. Máscaras antigases y mascarillas, antiparras, utensilios de primeros auxilios, bicarbonato para el efecto de las bombas lacrimógenas y de escudos improvisados, hondas, en el caso de la primera línea de defensa.

El 25 de Octubre, tuvo lugar uno de los eventos más significativos del periodo. Ese día, alrededor de 1,2 millones de personas se manifestaron en Santiago, entre la Plaza Italia y el Palacio de la Moneda, bajo la convocatoria de "la marcha más grande en la historia de Chile". Fue una manifestación masiva, lúdica, festiva y pacífica a manera de contrarrestar la declaración de guerra del presidente y de su gobierno contra las protestas. Otros eventos similares ocurrieron a lo largo del país. La masiva y pacífica jornada del 25 , marcó un giro en la ocupación de la Plaza Italia, derrotando simbólicamente el discurso belicista del presidente Piñera (Navarro y Tromben 2019) y la difundida representación de los manifestantes como violentistas por los medios televisivos y escritos (Martuccelli 2019). El discurso de guerra de Piñera ni la performance bélica del gobierno y la televisión fueron capaces de generar un efecto de autenticidad y, por ende, no resultó creíble para la ciudadanía. En cambio la performance de la manifestación ciudadana generó tal nivel de autenticidad y credibilidad en sus reclamos (Alexander y Mast 2011), que posicionó legítimamente al movimiento de protesta frente a la ciudadanía en general (Alexander 2006; Paredes y Araya 2020). La manifestación opuso la fiesta y el carnaval a la guerra política del presidente, ganando en legitimidad social (Alexander 2010). 
La "Plaza de la Dignidad" como escenario de protesta...

Juan Pablo Paredes P.

Las manifestaciones continuaron, y aunque persistieron los enfrentamientos con la policía y con ello situaciones de violencia social, marcadas por la violación a los derechos humanos por parte de las fuerzas estatales (Martuccelli 2019), la ocupación de la plaza prosiguió de manera multitudinaria, pacífica y festiva, con la presencia de tambores, batucadas, música, cánticos, banderas de equipos de fútbol, la Wenüfoye (la bandera Mapuche), todo amparado en la credibilidad de las performances de protestas y la apropiación del espacio público por los manifestantes. Políticamente, tal credibilidad y respaldo a la performance de protesta, derivó en un cambio de gabinete ministerial a fines de octubre (Somma et al. 2020; Palacios 2020).

La presencia masiva de manifestantes y su ocupación de la plaza, como de su entorno, junto con las performances- actos singulares y prácticas rutinarias- fueron elaborando más elementos que reforzaron su identificación colectiva. A los motivos ya señalados se sumaron, "nos costó tanto encontrarnos, no nos soltemos", para señalar la recomposición del lazo social entre ciudadanos, a partir de las protestas; "nos volvimos a llamar pueblo", a manera de remarcar la base popular de la demanda ciudadana; o el reconocimiento de la necesaria unidad de las barras, distanciadas por motivos deportivos, pero unificadas en base al compromiso con la causa popular, bajo la consigna "perdimos mucho tiempo peleando entre nosotros". Cada uno de estos enunciados afirmativos, refuerzan la representación de un nosotros colectivo derivado del proceso. En adelante la lucha debía ser contra la élite, especialmente el gobierno y el mundo político, por eso tales consignas se acompañaron del "renuncia Piñera", para conformar el eje de identificación antagónica (Flesher Fominaya 2010; Laclau 2005). "No estamos en guerra/estamos unidos" fue el contra-enmarcado que gozó de gran credibilidad pública y social, reforzando la credibilidad del performance y el discurso de la movilización (Alexander y Mast 2011), generando un clima emocional distinto al que fomentaban los medios y el gobierno.

El 12 de noviembre se realizó una huelga general, convocada por Unidad Social, con el respaldo de fuerzas sociales y políticas, que se suman al esfuerzo ciudadano de los manifestantes y activistas, revitalizando la presencia de personas en las calles- que habían empezado a participar de otros espacios más territoriales como asambleas y cabildos- y dando un empuje a la ocupación de la Plaza Italia. Tres semanas de protestas en Plaza Italia, forjaron lazos entre los manifestantes permitiendo su consolidación posterior. Las interacciones constantes y relaciones sociales entre manifestantes, fueron generando un sentimiento compartido de reconocimiento recíproco, en las que el orgullo y la dignidad fueron las emociones morales fundantes del compromiso manifestante (Poma y Gravante 2015), generando un clima de esperanza social en la Plaza y su entorno, al punto que el lugar fue refundado por los manifestantes como "Plaza de la Dignidad", como significante maestro de la emoción que acompañó las protestas durante los meses venideros.

La manifestación, pasadas más de tres semanas, se inscribió en el espacio público y se apropió de la Plaza de la Dignidad y sus alrededores, difundiendo el motivo "hasta que la dignidad se haga costumbre", que resalta la capacidad de agencia del movimiento de

Revista de Humanidades de Valparaíso, 2021, No 17, 27-52

(c) $(1)(9)$ CC BY-NC-ND 
La "Plaza de la Dignidad" como escenario de protesta...

Juan Pablo Paredes P.

protesta (Gamson 1992), a partir de la transformación de las emociones morales y su posterior condensación como fuente de la identificación del movimiento de protesta (Paredes y Otárola 2019; Gravante 2020). La rabia colectiva y la indignación moral inicial, generadas por el contexto de injusticia, dio pasó a la elaboración de un sentimiento compartido de esperanza, orgullo y dignidad, constituyendo la batería moral (Jasper 2016), que sostuvo el acontecimiento de Octubre. La ocupación de la plaza y su cambio de nombre, resalta la importancia de las emociones (Poma y Gravante 2015; Jasper 2016; 1997) y de los afectos (Taylor 2013), de la sociabilidad y de experiencias compartidas (Pleyers 2010), de la identificación colectiva y la definición de opositores (Flesher Fominaya 2010), junto con la existencia de espacios libres de las restricciones del modelo económico y político (Polleta 1999).

"Hasta que la dignidad se haga cuerpo y lugar" nos dijeron y mostraron los manifestantes en la Plaza de la Dignidad, reconocida como tal por las ciudadanías manifestantes como por el mundo popular. Esa dignidad y esperanza que se materializó en otros artefactos y performances, más allá de la apropiación espacial. Surgieron símbolos e íconos (Alexander 2012; 2011), que materializaron otros significados y consolidaron los encuadres ya descritos.

\subsection{Los íconos del movimiento de protesta y el encuadre musical}

La dignidad y la esperanza se incorporaron en los cuerpos manifestantes (Taylor 2013), y en objetos culturales (Alexander 2012; Hall 1997), como formas de materialización de los significados sociales. Entiendo a estos como íconos, es decir, un objeto material portador de sentidos estéticos y morales que entra en resonancia con el contexto cultural y alcanza fuerza material y poder simbólico (Alexander 2012; 2010). Un modo de condensación simbólica de sentidos sociales, materializada en artefactos y objetos, permitiendo formas de clasificación cognitiva y moral de la vida social (Alexander 2010).

Las manifestaciones en la plaza abarcaron a grupos etarios, socioeconómicos e ideológicos diversos, aunque se resalta la participación juvenil (Núcleo de Sociología Contingente 2019). Siempre estuvieron presentes la bandera chilena y mapuche, sin embargo las banderas de los partidos políticos no fueron autorizados por los manifestantes a participar en ellas (Palacios 2020; Márquez 2020; Lin 2019).

La ausencia de banderas políticas, contrasta con la presencia frecuente de la bandera chilena de color negro, siendo uno de los símbolos del movimiento de protesta de Octubre. Ella representa la figura del duelo y el luto, la tristeza y el dolor por la pérdida de vidas, de la visión, la mutilación, la tortura y la represión, encarnando una forma homenaje a los caídos y de denuncia pacífica del abuso policial y en especial de las violaciones a los derechos humanos, ocurridas en las protestas. Al mismo tiempo, el color negro expresa un gesto de resistencia y desobediencia frente a las injusticias que justifican las mani- 
La "Plaza de la Dignidad" como escenario de protesta...

Juan Pablo Paredes P.

festaciones. De tal forma, la bandera negra mediante su resonancia cultural posibilita la emergencia significados afectivos, morales y políticos, asociados al dolor del duelo social y a la resistencia popular, transformando la bandera en un ícono del movimiento de protesta, que sobrepasa al objeto para producir un efecto sensible y moral compartido entre activistas y públicos (Alexander 2010; Bartmánski y Alexander 2012).

La persistencia de la manifestación por tanto tiempo, se debe en parte, a la capacidad de producir símbolos e íconos que refuerzan el sentimiento compartido entre los manifestantes, de resistir, defenderse y cuidarse, reforzando su eficacia simbólica (Alexander y Mast 2011). Jasper (2016), señala que en las protestas los manifestantes emplean diferentes formas de transmitir significados, como el cuerpo o los íconos, entre ellas destacan los portadores figurativos, como personajes que representan a héroes, villanos y víctimas en un conflicto y que posibilitan representar ciertas emociones morales. La primera línea de defensa y salud, simbólicamente encarnaron emociones de cuidado y compromiso, actuando como héroes (Jasper 2016), en tanto fueron capaces de realizar acciones extraordinarias en beneficio de otros. Para lograr tal eficacia simbólica contaron con la ayuda de íconos heroicos, encarnados en personajes de la cultura popular, como el "estúpido y sensual Spiderman", "Pikachú" o "Pareman", que junto a la figura del Negro Matapacos, conformaron parte de los llamados "Avengers chilenos", para enfrentar a la élite económica y política, en tanto encarnan a los villanos.

Los vengadores chilenos son un conjunto de héroes icónicos que fomentaron, junto con la primera línea, un sentimiento de orgullo, confianza y compromiso entre los manifestantes, permitiendo la emergencia de su consciencia icónica (Alexander 2011; 2010), esto es la condensación de un sentimiento colectivo, una evaluación moral compartida y una fuerza estética común (Bartmánski y Alexander 2012). Sobre algunos de ellos se constituyó una narrativa en torno al personaje que reforzó su aura moral y permitió el desarrollo de la consciencia icónica de los manifestantes. Así, la figura del Negro Matapacos es la representación del perro negro que, con su pañuelo rojo al cuello, acompañó múltiples jornadas de protestas de la movilización estudiantil del ciclo 2011-2017, luchando "codo a pata" con los estudiantes contra la represión policial. Pareman, un encapuchado de la primera línea, cuyo distintivo es un escudo con el disco PARE del tránsito; el cuento popular nos habla de un joven con una trayectoria de abandono familiar y paso por los hogares del Servicio Nacional de Menores- institución muy cuestionada por el movimiento de protesta como fuente de las injusticias sociales-, por ende, encarna figurativamente al héroe de los descontentos. Estos personajes, y especialmente la primera línea como forma simbólica, son los héroes de la lucha callejera del Octubre.

Los mensajes también son importantes, y en los muros que rodean la Plaza Dignidad se inscriben aquellos que fueron conformando los motivos del encuadre. Algunos de los que identifica Márquez (2020) en su etnografía a la plaza, "Renuncia Piñera/ No + Abusos/Nueva Constitución / Asamblea Constituyente/ Justicia para las víctimas de la represión/Convocatoria constitucional ahora". Junto a ellos, se refuerza el encuadre agencial

Revista de Humanidades de Valparaíso, 2021, No 17, 27-52

(c) $(1)(9)$ CC BY-NC-ND 
La "Plaza de la Dignidad" como escenario de protesta...

Juan Pablo Paredes P.

del movimiento de protesta (Gamson 1992; Paredes y Otárola 2019), expresadas en las claves de Chile despertó/ Cuida al Piño/ La calle no calla, debate que estalla. Complementariamente, se configuró todo una escena sonora sustentada en la música. La Plaza de la Dignidad produjo una infraestructura cultural y organizacional (Williams 2010; Jasper 2016) como soportes materiales, de acciones y relaciones, por ejemplo, la entrega de agua y comida gratuita para manifestantes. Destaca la conformación de la Radio Plaza de la Dignidad y la banda dignidad, que favorecieron la circulación de producciones musicales asociadas a la protesta (Williams 2010; Rosenthal y Flacks 2011).

Particularmente, la Radio facilita la recuperación de las memorias de luchas precedentes, mediante la reiteración frecuente de la música. "El pueblo unido" en la interpretación de Inti-Illimani, reforzó la cohesión y compromiso del nosotros; "El baile de los que sobran" de los Prisioneros, que reposicionó el tema de la desigualdad y la injusticia; o "El derecho a vivir en paz" de Víctor Jara, como contrapunto a la violencia policial y la violación de los derechos humanos, coreados por los manifestantes en la plaza y sus alrededores, difundiéndose por redes sociales, alcanzando una resonancia cultural muy potente. A su vez, se difunde el nuevo repertorio de la manifestación con Anita Tijoux y su "Cacerolazo", que conjuga la demanda por la renuncia de Piñera, la denuncia por la represión y violencia policial, la capacidad de la manifestación para resistir al abuso (contextual y estructural), a partir del acto pacífico de cacerolear. Nuevamente hay acá un ejercicio de memoria, al recuperar una forma de protesta popular contra la dictadura, que también se utilizó durante las jornadas de protestas estudiantiles desde el 2011 (Ortiz 2019). Nos canta Tijoux: No son treinta pesos, son treinta años/La constitución, y los perdonazos/Con puño y cuchara frente al aparato/Y a todo el Estado, ;cacerolazo!

Se refuerza la denuncia de la represión policial y la violación a los derechos humanos en la canción de Alex Andwanter, "Paco Vampiro", rebautizando a carabineros con esa etiqueta. La canción inicia dando cuenta del abuso represivo de manera contextual y estructural, "Un país con olor a lacrimógena/ Ya van treinta años y no se va", nos dice, y luego pregunta “¿Cómo pides paz mientras torturas?/ ¿Cómo pides paz mientras matas? Formulando un cuestionamiento moral compartido por los manifestantes, activistas y las audiencias ciudadanas favorables a la movilización.

En "Bandera Negra", el rápero Kanitrou, acentúa la lucha social mediante "el pueblo unido dando cara resistiendo", resaltando la capacidad de agencia de la manifestación, con un motivo propio del contexto de protesta. Dar cara significa el valor y la capacidad para enfrentar la violencia, en la presencia de la primera línea, de los activistas en el espa-

\footnotetext{
${ }^{1} \mathrm{https}: / /$ www.youtube.com/watch?v=lItbHicquo4

${ }^{2} \mathrm{https}: / /$ www.youtube.com/watch? $\mathrm{v}=\mathrm{tdtpGRR}-8 \mathrm{wU}$

${ }^{3}$ https://www.youtube.com/watch?v=6HjOyF0B39M
} 
La "Plaza de la Dignidad" como escenario de protesta...

Juan Pablo Paredes P.

cio público, así como los estudiantes evadiendo al inicio del acontecimiento de Octubre. Es un refuerzo mediante símbolos del framing moral y emocional del proceso (Paredes y Otárola 2019).

En todas ellas resuenan los motivos cognitivos y morales que sostienen el acontecimiento de Octubre, como es la apelación a los más de treinta años de injusticias y desigualdad desde el regreso a la democracia (Palacios 2020) o la permanencia de la constitución ilegítima de 1980 y la necesidad de una nueva constitución (Heiss 2020), o la desigualdad de trato con el mundo empresarial y político por sus actos de corrupción (Somma et al. 2020). Expresan parte de los motivos de las manifestaciones, a modo de justificación pragmática por su ocurrencia.

La utilización de estos recursos simbólicos (música y rayados) e iconográficos (objetos y personajes), configuraron la praxis cultural del movimiento de protesta (Eyerman y Jamison 1998). Las canciones analizadas, aportan a la consolidación de la identificación colectiva del movimiento, el encuadre moral y afectivo, como a la interpelación política al gobierno y al Estado. Estos encuadres cognitivos, morales y emotivos, en conjunto con la fuerza icónica de los héroes, constituyeron el poder icónico y simbólico del movimiento de protesta.

\section{El paisaje: de las resistencias a las solidaridades. Una propuesta de interpretación}

Ambas perspectivas, la SC (Alexander 2006) y los EECC (Hall 1988), han prestado bastante atención a los alcances de la acción simbólica ciudadana en la configuración de la sociedad civil. Propongo que captar la acción simbólica de las protestas del acontecimiento de Octubre, a partir de artefactos, frames y performances, en sus efectos para la sociedad civil, es una forma de aplicar la propuesta interpretativa de Reed (2011). En base al análisis anterior, los efectos pueden observarse tanto en la configuración de un discurso ideal sobre la sociedad civil (Alexander 2006), como en prácticas de significación que permiten otras formas para su reconstrucción (Hall 1988).

La narración precedente permite configurar un paisaje de sentido a partir de dos escenas diferenciadas, aunque interconectadas y en tensión. La primera fue bien definida ese primer mes y la otra estaba recién en formación durante las primeras semanas. La resistencia confrontacional es la primera escena, materializada en el artefacto Plaza de la Dignidad, sus performances y sus encuadres, expresadas en la denuncia, el reclamo y la protesta, con actores perfilados y las tareas definidas. "Son treinta años" de injusticia, desigualdad y abusos, denunciadas a través de la acción simbólica de la protesta. La respuesta de la institucionalidad política, en general, fue la oposición y el rechazo a la manifestación por su carácter violento, en particular la del Gobierno, fue la represión excesiva y la violación de los derechos humanos (ACNUDH 2019). La alternativa del movimiento de protesta fue resistir. Para ello se conformó la primera línea de defensa y

Revista de Humanidades de Valparaiso, 2021, No 17, 27-52

(c) $(1)(9)$ CC BY-NC-ND 
La "Plaza de la Dignidad" como escenario de protesta...

Juan Pablo Paredes P.

cuidado, se elaboró un encuadre basado en los sentimientos morales de la indignación y la dignidad, se generó una consciencia icónica sustentada en figuras heroicas que producen un orgullo hacia la movilización popular y ciudadana, definiendo también a sus villanos (Jasper 2016).

De lo anterior se colige una estructura cultural de la sociedad civil (Alexander 2003; 2006) en torno a la resistencia confrontacional, en las que los manifestantes conforman un nosotros digno, justo y valiente, versus unas autoridades políticas y económicas injustas, corruptas e indignas. El espacio público, la plaza y la calle eran arenas virtuosas y sacras (Alexander 2006), pues promueven la justicia y la igualdad social, mientras los espacios institucionales son profanos y viciosos ("la cocina" del acuerdo constitucional del 15 de Noviembre), pues producen desigualdad y exclusión. Configurando un ideal abstracto de solidaridad cuyo rasgo es la pureza social y la no contaminación institucional, que generó como efecto una frontera antagónica entre posiciones polarizadas, posibles de identificar como popular e institucional durante ese primer mes.

Junto a tal estructura cultural, a partir de la observación participante y la conversación situacional, es posible rastrear una segunda escena, emergente en las últimas semanas del primer mes, asociada a prácticas de significación y de decodificación (Hall 1980) que escapan a la anterior clasificación binaria. Tales posiciones asumieron la apertura al diálogo y la conversación como forma práctica de significación, por sobre la protesta aunque participaron de ella. Bajo la forma de asambleas territoriales o comunitarias y cabildos ciudadanos, se fueron configurando otros espacios que se dieron de manera complementaria a la apropiación de la Plaza de la Dignidad y de otras plazas, incluso algunas funcionaron al interior de ellas, estableciendo un modo de resistencia ciudadana que apuntó a la conformación de una asamblea constituyente, conformando diversos microespacios de deliberación, como forma de resistencia propositiva, que surgió a partir de, y gracias a, la acción simbólica de la resistencia confrontacional.

En estos artefactos asamblearios, la pluralidad de posiciones es constitutiva y no puede condensarse fácilmente en expresiones duales, por ende, la resistencia no fue solo confrontacional o subordinada a las decisiones de la autoridad política, aunque recurrieron a una distancia crítica hacia ellas. Más bien aplicaron formas negociadas de intercambios y decodificación (Hall 1980) de las demandas populares, generando modos diversos de resignificación de las mismas. De tal forma, fueron emergiendo posiciones que favorecían algún tipo de intercambio con los partidos políticos y con fuerzas sociales ya constituidas, mientras que otras posiciones rechazaron tales acercamientos o algunos de ellos - dependiendo de las fuerzas políticas -, configurándose un arco amplio de alternativas híbridas para producir posiciones diversas desde la sociedad civil. Alternativas invisibilizadas en los análisis que no consideran la dimensión cultural en su complejidad, como los de Peña (2020) o Waissbluth (2020).

Revista de Humanidades de Valparaíso, 2021, No 17, 27-52

(c) $(1)(9)$ CC BY-NC-ND 
La "Plaza de la Dignidad" como escenario de protesta...

Juan Pablo Paredes P.

En el interfaz entre la modalidad de resistencia confrontacional y de resistencia propositiva, surgieron variadas formas prácticas de solidaridad, en la que se ven la horizontalidad, el apoyo mutuo, la colaboración y el dialogo con pretensiones de generalización. La segunda escena fomenta una solidaridad en práctica y desde abajo (Hall 1980), por ende, menos pura e ideal. Más bien, es una experiencia vivida irreductible a principios, aunque refieren también a ellos. Una suerte de estructura de sentir solidario (Williams 2003), como un conjunto emergente de expresiones, actuaciones y prácticas de solidaridad, en formas de colaboración entre manifestantes, activistas, simpatizantes y ciudadanos no movilizados, que se producen en los intersticios de los espacios de confrontación y de negociación. Tales formas prácticas fueron la base de muchas de las experiencias de solidaridad en práctica que se dieron durante el primer semestre del 2020, en los meses de pandemia y que se tradujeron en ollas comunes y otras experiencias de enfrentar colectivamente la crisis sociosanitaria.

Las formas de solidaridad concreta no rehúyen de la resistencia confrontacional ni la marginan, pues saben que junto con ser un derecho, es una posibilidad contingente, aunque intentan desplegar también otros recursos político-culturales. Esta segunda escena se asoció más a las prácticas de la sociedad civil que articulan la resistencia propositiva y la desobediencia civil, que a una estructura ideal sustentada en la confrontación, aunque siempre se las vea con ella. Tensión posible de rastrear entre prácticas de colaboración, formas de solidaridad y los horizontes ideales que surgen de ellas.

De tal forma tenemos un paisaje de sentido tensionado entre resistencias y solidaridades, que da forma a dos representaciones diferenciadas de la sociedad civil. La de la solidaridad ideal a partir del paisaje de la resistencia confrontacional, y por otro las solidaridades en práctica, a partir de la interfaz de resistencia propositiva y confrontacional, que descentra la Plaza de la Dignidad para encontrar otros lugares y otros territorios, cargados también ellos de sentimientos morales. Ambas escenas se cruzaron post-acuerdo del 15 de Noviembre, configurando otros paisajes de sentido que no he considerado acá- por ejemplo el del proceso constitucional-. Las formas en que estos paisajes de la sociedad civil se articulen, o no, fue pospuesta y tendremos que esperar hasta el inicio de la convención constitucional y el fin de la pandemia para tener mayor claridad de ellos. Pero debe tenerse en consideración, siguiendo a R. Williams (1997), que las posibilidades deben verse en un arco que va de lo dominante hasta lo emergente, pasando por lo residual, por ende, el proceso sigue abierto y sin garantía (Hall 1988) de éxito, para ninguna de las representaciones acá formuladas.

\section{Conclusión}

De acuerdo al paisaje de sentido interpretado, puedo señalar a manera de hipótesis que las lógicas culturales identificadas por Araujo (2019), sufrirán ciertos impactos. Desde el comienzo de las protestas, en un impulso que viene desde antes del 2011, se produjo una

Revista de Humanidades de Valparaiso, 2021, No 17, 27-52

(c) (1) @ $\odot$ CC BY-NC-ND 
La "Plaza de la Dignidad" como escenario de protesta...

Juan Pablo Paredes P.

desnaturalización de las jerarquías sociales asentadas en los últimos treinta años, junto con una crítica a la élite política y económica, cuestionando su estatus (PNUD 2019). La vida pública en Chile ya no será exclusivamente la de las élites, como lo deja ver la discusión sobre la inclusión de independientes en el proceso constituyente 2021. Segundo, se han originado formas de autoridad horizontal y recíproca entre activistas y manifestantes, que rechazan las formas autoritarias. En base a las interacciones y sociabilidades presentes tanto en la resistencia confrontacional como en la propositiva, dejando ver expresiones de colaboración y apoyo mutuo que permiten otras formas de reconocimiento. Un ejemplo de esto, fueron las rápidas respuestas de las asambleas territoriales y comunales, las juntas de vecinos y asociaciones barriales, a la crisis sanitaria para enfrentarla colectivamente, al punto que hoy reclaman un espacio en el proceso constituyente. Tercero, la lógica de la confrontación de poderes y fuerzas se mantiene, aunque la cancha se ha equilibrado producto de la politización de la vida social (PNUD 2015; 2019).

Por cierto existen otras escenas del proceso que pueden configurar otros paisajes o modificar el propuesto acá, complejizando el análisis, como por ejemplo las violencias populares y los saqueos, las escenas mediales y de redes sociales, la irrupción feminista post acuerdo de noviembre, con sus propios símbolos e íconos (las tesis, el pañuelo verde), entre otros. Sin embargo, uno de los méritos del trabajo es la proyección del acontecimiento de Octubre en clave político-cultural hacia la sociedad civil.

Ya sea se entienda como una representación de la solidaridad abstracta, sustentada en una acción de resistencia confrontacional que proyecta un ideal desde un escenario altamente polarizado, o bien una representación de diversas prácticas solidarias, sustentadas en una resistencia desobediente y propositiva que proyecta una suerte de estructura del sentir solidario que puede alcanzar diversas formas, y no una estructura cultural. Ambas proponen la vinculación entre los modos de hacer colectivo y la formulación de horizontes sociales de sentido, porque la batalla por los significados de las crisis, importan (Pleyers 2020), se deben considerar tanto las actuaciones de protestas como las prácticas colectivas de esperanza (Santos 2020). En razón de lo anterior, se puede interpretar simbólicamente el desencanto popular con el acuerdo de Noviembre, al descartar la etiqueta de asamblea constituyente. Por último, el actual escenario previo al proceso constitucional de abril 2021, permite observar la presencia de las dos formas de representación de la sociedad civil en el debate sobre las formas de participación ciudadana en la convención constitucional.

Desde un punto de vista analítico, Eyerman (2004), señala que existe cierta deficiencia en la sociología cultural de Alexander, en relación al estudio del poder, y sugiere que podría beneficiarse con algunas ideas de los EECC, en especial de S. Hall (1980). Coincidiendo, en este trabajo he tratado de tantear la posibilidad de un acercamiento entre ambos programas, aplicados a los movimientos de protesta, aunque con una preeminencia de la sociología cultural. Señalo que es importante matizar la idea de autonomía cultural

Revista de Humanidades de Valparaíso, 2021, No 17, 27-52

(c) $(1)(9)$ CC BY-NC-ND 
La "Plaza de la Dignidad" como escenario de protesta...

Juan Pablo Paredes P.

en términos empíricos, para vincularla de forma más adecuada a los problemas relativos al vínculo cultura y poder. En ese terreno los aportes de Williams y Hall, me parecen de primer orden.

Por último desde un punto metodológico y epistémico, considerando el vínculo entre ciencias sociales y humanidades, propongo que la investigación de este tipo requiere una prueba situacional, donde la interpretación se propone como una comprensión razonable y plausible de los significados sociales a través actuaciones, prácticas, símbolos e íconos que los evidencien para realizar una reconstrucción adecuada y amplia del paisaje de sentido del acontecimiento. No obstante, esa construcción debe acompañarse de una interpretación pragmática de los efectos (Reed 2011; 2008). Esto implica que la investigación de estos temas parta desde la acción y experiencia de los actores, y sus relaciones, a través de la contextualización de los sentidos de la acción que se realizan en un momento particular (Reed 2011), para posteriormente vincularlos con los alcances institucionales y estructurales relacionados con el poder, la hegemonía o la ideología (Hall 2016).

Lo que he formulado es una pequeña contribución para el acercamiento entre las herramientas de los estudios culturales y la sociología cultural, con el fin establecer posibilidades de diálogo entre ambos programas en el estudio cultural de las protestas sociales. Con ello, aliento desde la investigación empírica de las ciencias sociales, a superar la miopía de nuestras disciplinas con las humanidades y el arsenal de herramientas que nos aporta para dar cuenta interpretativamente de la vida social.

\section{Agradecimientos}

El artículo es parte del proyecto CONICYT REDI 170473. Agradezco el apoyo de ANID (ex CONICYT) por el financiamiento.

\section{Referencias bibliográficas}

ACNUDH (2019). Informe sobre la misión a Chile. 30 Octubre a 22 de Noviembre 2019. Naciones Unidas. Recuperado de https://www.ohchr.org/Documents/Countries/CL/Report_Chile_2019_SP.pdf

Alexander, Jeffrey (2012). Iconic Power and Performance: The Role of the Critic. En Jeffrey Alexander, Dominik Bartmánski, Bernard Giesen (eds.), Iconic Power. Materiality and Meaning in Social Life (pp. 25-35). New York: Palgrave Macmillan. https://doi. org/10.1057/9781137012869_3

Alexander, Jeffrey (2011). Fact-signs and cultural sociology: How meaning-making liberates the social imagination. Thesis Eleven, 104(1), 87-93. https://doi.org/10.1177/0725513611398623

Alexander, Jeffrey (2010). Iconic Consciousness: The material feeling of meaning. Thesis Eleven, 103(1), 10-25. https://doi.org/10.1177/0725513610381369

Revista de Humanidades de Valparaíso, 2021, No 17, 27-52

(c) $(1)(9)$ CC BY-NC-ND 
La "Plaza de la Dignidad" como escenario de protesta...

Juan Pablo Paredes P.

Alexander, Jeffrey (2006). Civil Sphere. Oxford: Oxford University Press.

Alexander, Jeffrey (2003). The Meaning of Social Life. A Cultural Sociology. Oxford: Oxford University Press.

Alexander, Jeffrey, Mast, Jason (2011). The Cultural Pragmatics of Symbolic Action. En Jeffrey Alexander (2011). Performance and Power (pp. 7-24). Cambridge: Cambridge University Press.

Araujo, K. (2019). Desmesuras, desencantos, irritaciones y desapegos. En K. Araujo (ed.), Hilos tensados. Para leer el Octubre chileno (pp. 15-36). Santiago de Chile: Editorial Usach.

Berroeta, Héctor, Sandoval, Juan (2014). Protestas, participación y educación pública: discursos sobre lo público en las movilizaciones estudiantiles en Chile. Educar em Revista, 53, 1938. https://doi.org/10.1590/0104-4060.36578

Bartmánski, Dominik, Alexander, Jeffrey (2012). Materiality and Meaning in Social Life: Toward an Iconic Turn in Cultural Sociology. En Jeffrey Alexander, Dominik Bartmánki and Bernard Giesen (eds.), Iconic Power. Materiality and Meaning in Social Life (pp. 1-12). New York: Palgrave MacMillan.

Cefaï, Daniel (2011). Diez propuestas para el estudio de las movilizaciones colectivas. Contexto de experiencias y problemas públicos. Revista de Sociología de la Universidad de Chile, 26, 137-166. https://doi.org/10.5354/0719-529X.2011.27491

Celikates, Robin (2016). Rethinking Civil Disobedience as a practice of contestation: Beyond the liberal paradigm. Constellations, 23(1), 37-45. https://doi.org/10.1111/1467-8675.12216

Centro Derechos Humanos-UDP (2012). Informe Anual DDHH en Chile. Santiago: UDP. Recuperado de http://www.derechoshumanos.udp.cl/derechoshumanos/informe-ddhh-2012/

Cuevas, Hernán, Paredes, Juan Pablo (2018). Esfera pública, actos de ciudadanía y arenas públicas: la redefinición de la educación y del espacio público por las protestas estudiantiles en Santiago (2011-2015). En Nicolás Del Valle (ed.), Transformaciones de la esfera pública en el Chile neoliberal: luchas sociales, espacio público y pluralismo informativo (pp. 3968). Santiago: RIL/UCEN.

COES - Observatorio de Conflictos (2020). Informe anual Observatorio de Conflictos. Santiago: COES.

Eyerman, Ron (2004). Jeffrey Alexander and the Cultural Turn in Social Theory. Thesis Eleven, 79(1), 25-30. https://doi.org/10.1177/0725513604046953

Eyerman, Ron, Jamison, Andrew (1998). Music and Social Movements. Cambridge: Cambridge University Press.

Fernández, Roberto (2013). El espacio público en disputa: Manifestaciones políticas, ciudad y ciudadanía en el Chile actual. Psicoperspectivas, 12(2), 28-37. https://dx.doi.org/10.5027/ psicoperspectivas-Vol12-Issue2-fulltext-278

Fillieule, Olivier, Tartakowsky, Danielle (2015). La manifestación. Cuando la acción colectiva toma la calle. Buenos Aires: Siglo XXI.

Revista de Humanidades de Valparaíso, 2021, No 17, 27-52

(c) $(1)(9)$ CC BY-NC-ND 
La "Plaza de la Dignidad" como escenario de protesta...

Juan Pablo Paredes P.

Fisher-Litche, Erika (2011). Estética de lo performativo. Madrid: Abada.

Flesher Fominaya, Cristina (2010). Collective Identity in Social Movements: Central Concepts and Debates. Sociology Compass, 4(6), 393-404. https://doi.org/10.1111/j.17519020.2010.00287.x

Gamson, William (1992). Talking Politics. Cambridge: Cambridge University Press.

Gravante, Tommaso (2020). Emociones y reglas del sentir como impactos culturales de los movimientos sociales. Interdisciplina, 8(22), 157-179. http://dx.doi.org/10.22201/ceiich.24485705e.2020.22.76423.

Hall, Stuart (2016). Cultural Studies 1983. A Theoretical History. Durham: Duke University Press.

Hall, Stuart (1997). The Work of Representation. En Stuart Hall (ed.), Representation: Cultural Representations and Signifying Practices (pp. 13-74). London: Sage.

Hall, Stuart (1988). The hard road to renewal: Thatcherism and the crisis of the left. London: Verso.

Hall, Stuart (1980). Encoding/decoding. En Stuart Hall, Dorothy Hobson, Andrew Love, Paul Willis (eds.), Culture, media, language (pp. 128-138). London: Hutchinson.

Heiss, Claudia (2020). ¿Por qué necesitamos una Nueva Constitución? Santiago de Chile: Editorial Aguilar.

HRW (2019). Chile: Police reforms needed in the wake of protests. Human Rights Watch. Recuperado de https://www.hrw.org/news/2019/11/26/chile-policereforms-needed-wake-protests

Jasper, James (2016). Protesto. Uma introducao aos movimentos sociais. Rio de Janeiro: Zahar.

Jasper, James (2010). Social Movement Theory Today: Toward a Theory of Action? Sociology Compass, 4(11), 965-976. https://doi.org/10.1111/j.1751-9020-2010.00329.x

Jasper, James (1997). The art of moral protests. Culture, biography and creativity in the social movements. Chicago: The University of Chicago Press.

Johnston, Hank (2016). Dimensions of Culture in Social Movements Research. En David Inglis y Anna-Mari Almila (eds.), The SAGE Handbook of Cultural Sociology (pp. 414-428). London: Sage.

Laclau, Ernesto (2005). La razón populista. Buenos Aires: Fondo de Cultura Económica.

Lin, Tai (2019). Hasta que la (plaza de la) Dignidad se haga costumbre. Violencias y espacio público en la protesta metopolitana. En K. Araujo (ed.), Hilos tensados. Para leer el Octubre chileno (pp. 299-314). Santiago de Chile: Editorial Usach.

Lima Neto, Fernando (2014). Cultural sociology in perspective: Linking culture and power. $\mathrm{Cu}$ rrent Sociology, 62(6), 928-946. https://doi.org/10.1177/0011392114533212

Márquez, Francisca (2020). Por una antropología de los escombros. El estallido social en plaza Dignidad, Santiago de Chile. Revista 180(45), 1-13. http://dx.doi.org/10.32995/rev180. Num-45.(2020).art-717

Revista de Humanidades de Valparaíso, 2021, No 17, 27-52

(c) $(1)(9)$ CC BY-NC-ND 
La "Plaza de la Dignidad" como escenario de protesta...

Juan Pablo Paredes P.

Martuccelli, Danilo (2019). El largo Octubre chileno. Bitácora sociológica. En K. Araujo (ed.), Hilos tensados. Para leer el Octubre chileno (pp. 369-476). Santiago de Chile: Editorial Usach.

Morales, Mauricio (2020). Estallido social en Chile 2019: participación, representación, confianza institucional y escándalos públicos. Análisis Político, 33(98), 3-25. https://doi. org/10.15446/anpol.v33n98.89407

Núcleo de Sociología Contingente (2019) Encuesta Zona Cero. Universidad de Chile. Recuperado de: https://nudesoc.cl/images/informe $\% 20 \mathrm{de} \% 20$ resultados $\% 20$ para $\% 20 \mathrm{p} \% \mathrm{C} 3 \% \mathrm{~A} 1$ gina.pdf

Navarro, Federico, Tromben, Carlos. (2019). Estamos en guerra contra un enemigo poderoso, implacable: los discursos de Sebastián Piñera y la revuelta popular en Chile. Literatura y lingüistica, 40, 295-324 https://dx.doi.org/10.29344/0717621x.40.2083

Ortiz, Nicolás (2019). Cacerolazo: emociones y memorias en el movimiento estudiantil 2011. Polis, 53, 66-77. http://dx.doi.org/10.32735/S0718-6568/2019-N53-1385

Palacios, Indira (2020). Chile's 2019 October Protests and the Student Movement: Eventful Mobilization? Revista Ciencia Política, 40(3). Ahead of print.

Paredes, Juan Pablo, Araya, Camila (2020). La educación chilena, ¿no se vende? Movilización estudiantil y la configuración del problema público universitario. Polis (Santiago), 19(57), 331-359. https://dx.doi.org/10.32735/s0718-6568/2020-n57-1573

Paredes, Juan Pablo, Otárola, Catalina (2019). El grito ciudadano en la lucha por el derecho a la educación: el marco moral y emocional de la movilización estudiantil en Chile (20112013). Sociológica, 98(34), 253-288.

Paredes, Juan Pablo (2013). Movilizarse tiene sentido: Análisis cultural en el estudio de movilizaciones sociales. Psicoperspectivas, 12(2), 16-23. https://dx.doi.org/10.5027/psicoperspectivas-Vol13-Issue2-fulltext-279

Peña, Carlos (2020). La revolución inhallable. Estudios Públicos, 158: 7-29. https://doi. org/10.38178/07161115/2020.001

Pleyers, Geoffrey (2020). Los movimientos sociales y la batalla por el significado de la crisis del coronavirus. Revista Pensamiento y Acción Interdisciplinaria, 6(1), 108-121. http://doi. org/10.29035/pai.6.1.108

Pleyers, Geoffrey (2010). Alter-Globalization. Becoming Actors in the Global Age. Cambridge: Polity.

PNUD, Chile (2019). Diez años de auditoria a la Democracia en Chile: antes del estallido. Santiago de Chile: PNUD, Chile. Recuperado de: https://www.cl.undp.org/content/chile/ es/home/library/diez-anos-de-auditoria-a-la-democracia--antes-del-estallido.html

PNUD, Chile (2015). Los tiempos de la politización. Santiago de Chile: PNUD-Chile. Recuperado de http://www.cl.undp.org/content/dam/chile/docs/desarrollohumano/Informe\%20 2015.pdf

Revista de Humanidades de Valparaíso, 2021, No 17, 27-52

(c) $(1)(9)$ CC BY-NC-ND 
La "Plaza de la Dignidad" como escenario de protesta...

Juan Pablo Paredes P.

Polletta, Francesca (2004). Culture is not just in your head. En Jeff Goodwin, James Jasper (eds.), Rethinking social movements: Structure, meaning and emotion (pp. 97-110). Oxford: Rowman \& Littlefield Publishers.

Polletta, Francesca (1999). "Free spaces" in collective action. Theory and Society, 28(1), 1-38.

Polletta, Francesca y Jasper, James (2001). Collective identity and social movements. Annual Review of Sociology, 27, 283-305.

Poma, Alice y Gravante, Tommaso (2015). Las emociones como arena de la lucha política. Incorporando la dimensión emocional al estudio de la protesta y los movimientos sociales. Revista Ciudadanía Activa, 3(4), 17-44.

Reed, Isaac (2011). Interpretation and Social Knowledge. Chicago: The University of Chicago Press.

Reed, Isaac (2008). Justifying Sociological Knowledge: From Realism to Interpretation. Sociological Theory, 26(2), 101-129.

Rosenthal, Robert y Flacks, Richard (2011). Playing for Change. Music and Musicians in the service of Social Movements. Boulder: Paradigm Plubishers.

Santos, Boaventura de Sousa (2020). Para alimentar la llama de la esperanza. Casa de las Américas, 298, 5-15.

Schuster, Federico (2005). Las protestas sociales y el estudio de la acción colectiva. En F. Schuster, F. Naishtat, G. Nardacchione y S. Pereyra (Comps.), Tomar la palabra. Estudios sobre protesta social y acción colectiva en la Argentina contemporánea (pp. 43-83). Buenos Aires: Prometeo.

Somma, Nicolás, Matías Bargsted, Rodolfo Disi y Rodrigo Medel (2020): No water in the oasis: the Chilean Spring of 2019-2020. Social Movement Studies, 20(4), 1-8. https://doi.org/10. $1080 / 14742837.2020 .1727737$

Swidler, Ann (1986). Culture in action: Symbols and strategies. American Sociological Review, 51, 273-286.

Swidler, Ann (1995). Cultural power and social movements. En Hank Johnston, Bert Klandermans (Eds.), Social movements and culture (pp. 25-40). Minneapolis, MN: University of Minnesota Press.

Tavera, Ligia, Johnston, Hank (2017). Artefactos de protesta en el campo del movimiento social mexicano: reflexiones en torno al 'hijastro' del análisis cultural. En Paul Almeida y Allen Cordero (eds.), Movimientos sociales en América Latina: perspectivas, tendencias y casos (pp. 113-140). Buenos Aires: CLACSO.

Taylor, Diana (2012). Performance. Buenos Aires: Asunto Impreso Ediciones.

Taylor, Diana (2013). The Politics of Passion. E-Misferica, 10(2). Recuperado de http://hemisphericinstitute.org/hemi/en/e-misferica-102/taylor

Revista de Humanidades de Valparaíso, 2021, No 17, 27-52

(c) $(1)(9)$ CC BY-NC-ND 
La "Plaza de la Dignidad" como escenario de protesta...

Juan Pablo Paredes P.

Ullrich, Peter, Daphi, Priska, Baumgarten, Pritta (2014). Protest and Culture: Concepts and Approaches in Social Movement Research - An Introduction. En Britta Baumgarten, Priska Daphi and Peter Ullrich (eds.), Conceptualizing Culture in Social Movement Research (pp. 1-22). London: Palgrave Macmillan.

Waissbluth, Mario (2020). Documento de trabajo: Orígenes Y Evolución Del Estallido Social. Recuperado de https://www.mariowaissbluth.com/descargas/mario_waissbluth_el_estallido_social_en_chile_v1_feb1.pdf.

Williams, Raymond (2003). La larga revolución. Buenos Aires: Nueva Visión.

Williams, Raymond (1997). Marxismo y Literatura. Barcelona: Península.

Williams, Rhys (2004). The cultural contexts of collective action: Constraints, opportunities, and the symbolic life of social movements. En David A. Snow, Sarah A. Soule \& Hanspeter Kriesi (eds.), The Blackwell companion to social movements (pp. 91-116). London: Blackwell.

Williams, Roy (2010). Reds, Whites, and Blues: Social Movements, Folks Music, and Race in the USA. Princeton: Princeton University Press. 